\title{
Changes in environmental release laws possible
}

\section{- OTA submits report to Congress - Tiered risk assessment proposed}

Washington

OptIONs for the regulation of the deliberate release of genetically-engineered organisms were presented yesterday to the US Congress in a report* from the Office of Technology Assessment (OTA). Although the report avoids making specific recommendations, its conclusions suggest that a shake-up in the regulation of biotechnology is necessary.

Congressional interest in deliberate environmental release has been spurred by gaps and overlaps in the regulations of the various agencies given responsiblity for biotechnology under the Coordinated Framework for the Regulation of Biotechnology. The Coordinated Framework, set up in 1986, is a patchwork of earlier regulations drawn from the Environmental Protection Agency (EPA), the Department of Agriculture, the National Institutes of Health and the Food and Drug Administration. Overall coordination is provided by the interagency Biotechnology Science Coordinating Committee (BSCC). But the agencies have yet to agree upon the definition of "genetically-engineered organism", and what is an environmental release.

Congressional efforts to force the agencies to tighten their regulations, and to confer statutory authority to the BSCC have failed so far. The current OTA report recommends the creation of another coordinating body with sufficient muscle to direct the preparation of review standards for field-tests among the various agencies

Currently, proposals to field-test genetically-engineered organisms undergo case-by-case review by the appropriate agency - a process that is likely to be swamped once the number of biotechnology products increases. OTA suggests a stratified scheme whereby only organisms that contain genes from a pathogen or which pose a chance of disrupting the ecosystem into which they are introduced would be subject to rigorous review; other field-tests would be evaluated by comparing them to previous ones.

Adequate assessment of the risks posed by field-tests will depend upon better data on the movement of genetically-engineered organisms in the environment, according to the OTA study. Such research overlaps disciplinary boundaries, and would be encouraged by the creation of an interagency task force or an increase in the level of funds for the study of natural selection, says OTA.

Despite the suggested changes, the OTA study concludes that "the adequate review of planned introductions is now possible". Even so, the report is more cautious than a similar assessment prepared by the National Academy of Sciences (see Nature 328, 653; 1987). Congress's reaction to the report will be gauged by whether the committees that requested it go on to submit legislation - a move that will probably be opposed by the biotechnology industry and the scientific community.

Carol Ezzell

* New Developments in Biotechnology-Field-Testing Engineered Organisms: Genetic and Ecological Issues. Office of Technology Assessment, Washington DC. 1988.

\section{Acrimonious debate over AIDS}

\section{Washington}

AIDS continues to arouse strong emotions in the US Senate, reflecting deep divisions within US society. Last week the Senate passed the "Federal AIDS Research Information and Care Act", co-sponsored by Senators Edward Kennedy (Democrat, Massachusetts) and Orrin Hatch (Republican, Utah) but not before the conservative Senator Jesse Helms (Republican, North Carolina) succeeded in adding a series of restrictive amendments.

The bill is intended to provide $\$ 700$ million for a comprehensive national plan to stem the spread of AIDS, for home and community care for AIDS patients, and for educational campaigns by both national and community organizations. Helms succeeded in adding amendments that barred any funds being spent on educational programmes that might condone homosexual behaviour. In a debate that was often angry, Helms said that he would "not allow one dollar of taxpayers' money to promote sodomy". He also succeeded in adding amendments that would make AIDS testing of sex and drug offenders compulsory and would ban plans to give clean needles to drug addicts.

In an attempt to reduce the damage caused by Helms, Kennedy succeeded in adding a further amendment to prevent the administration restricting "accurate information" about AIDS. The next step will be when the bill emerges from a subcommittee of the House of Representatives.

Alun Anderson

\section{"Non'" to man in space}

Paris

THE European Space Agency's longterm plan for manned space expeditions has little scientific justification, according to the Space Research Committee of the French Academy of Sciences. In a report just published, the committee concludes that "the principal justification for manned flights envisaged by European nations is to affirm their ability to put men into space with purely European means".

Since the principal components of ESA's plan were approved by member states, apart from Britain, at the interministerial meeting in The Hague last November, the Academy's report has come late in the day. But the findings should provide food for thought for ESA experts meeting in Strasbourg this week to discuss the manned missions. Ironically the two major elements in the ESA plan-the Hermes manned shuttle and the Ariane V launcher-are heavily backed by the French government.

ESA's science programme, which includes astronomy, Earth observation and microgravity experiments, will soon be capable of operating without the need for the presence of man. Indeed, such a presence "could be deleterious in the majority of space research operations". While some observations depend upon sensors in space, the report argues that remote operation from a ground station, or automatic data relaying are quite adequate. Furthermore, as satellites are often in orbits that are extremely hostile even for the well-protected astronaut, the role for man in the maintenance of satellites is also questionable.

Human intervention in some life science experiments aboard a space station will be necessary in the short term. For experiments on human physiology itself there is no alternative. But, says the report, such experiments do not, alone, justify European investment in manned space missions.

The Space Research Committee, whose report follows two years of study and debate in close liaison with the CNRS, the French national space research centre, feels that the desire to participate in the "human adventure" of manned space is "perfectly legitimate". What the committee fears-as the defender of purely scientific research-is that the high cost of putting man in space will take money away from basic science research "on the ground" in France. Such research, the committee argues, will be essential for the future success of Europe's space programme.

Peter Coles 